\title{
Working capability of composite wood-rubcon (rubber concrete) reinforced bridge beams under static loads
}

\author{
Fakhridin Boymatov ${ }^{1, *}$, Nikolay Nazarenko ${ }^{1}$ \\ ${ }^{1}$ Voronezh State Technical University, 84, 20-letiia Oktiabria str., 394006, Voronezh, Russia
}

\begin{abstract}
The results of experimental studies of the performance of bent composite wood-rubcon reinforced bridge beams under static loads are presented and the bearing capacity of composite wood-rubcon reinforced bridge beams is determined. A method for calculating wood-rubcon reinforced composite bridge beams is proposed.
\end{abstract}

\section{Introduction}

Wood is one of the first effective building materials from which man built housing, bridges and other structures. The main advantages of wood include light weight, ease of transportation and handling, chemical resistance, high mechanical strength, low sound and heat conductivity and, finally, frost resistance. The effectiveness of the use of wood-rubcon composite bridge beams can be increased by reinforcing the stretched area of the beams, which increases their strength and rigidity [1-8].

At present, wood with large diameters has become scarce, from which bridge and transverse beams were made, as well as sleepers. The direction of work associated with the reinforcement of the tensile zone of wooden composite bridge beams is an urgent task, as it makes it possible to work with wood of small diameters [9-12].

With the introduction of new double-layer wood-rubcon reinforced structures, it becomes necessary to experimentally and theoretically study the operation of wood-rubcon reinforced structures under static loads .

The purpose of the work was to determine the strength and deformability of woodrubcon reinforced composite bridge beams with transverse bending, to determine theoretical and experimental deflections and to compare experimental data with the results of theoretical calculations and to analyze the causes of possible deviations.

Scientific novelty of the work:

- the experimental and theoretical bearing capacity of wood-rubcon reinforced composite bridge beams has been determined;

- an analysis was made of the efficiency of compounds of wood with rubcon under static loads.

\footnotetext{
*Corresponding author: boymatov64@mail.ru
} 


\section{Production of wood-rubcon reinforced composite bridge beams}

Structurally, the wood-rubcon reinforced composite bridge beams consist of two layers, the first upper layer includes wooden beams (1) with the frame (2) (Figure 1.), then the second lower layer is made of rubcon (3) (Figure 2). Interlayer contact is reinforced with steel cage frames (Figures 3, 4). After laying the rubcon layer, the double-layer element is placed in a dry heating chamber, where the process of vulcanization occurs at a temperature $120 \pm 5^{\circ} \mathrm{C}$.

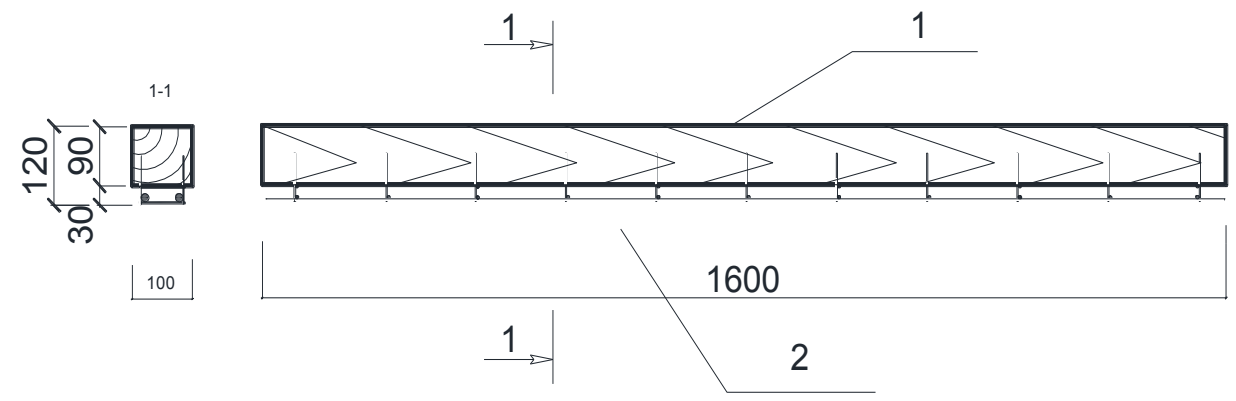

Fig. 1. Wooden beam with steel cage frame. Where:1- wooden beam, 2- steel cage frame (SNKR-1).

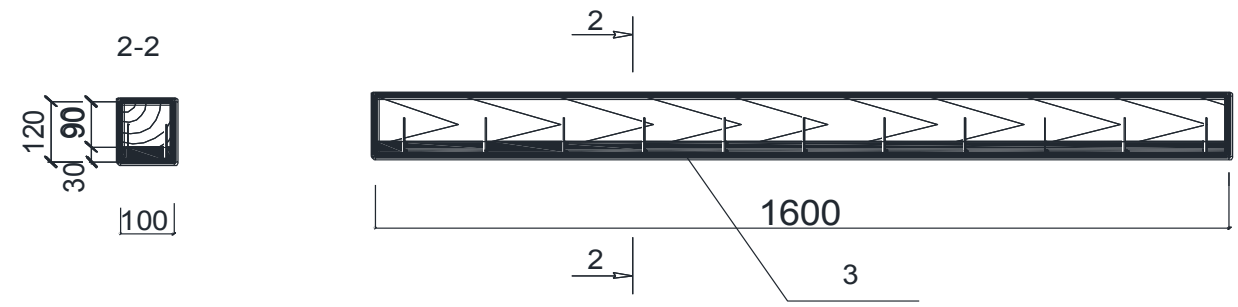

Fig. 2. A wood-rubcon reinforced composite bridge beam. Where: 3-rubcon.

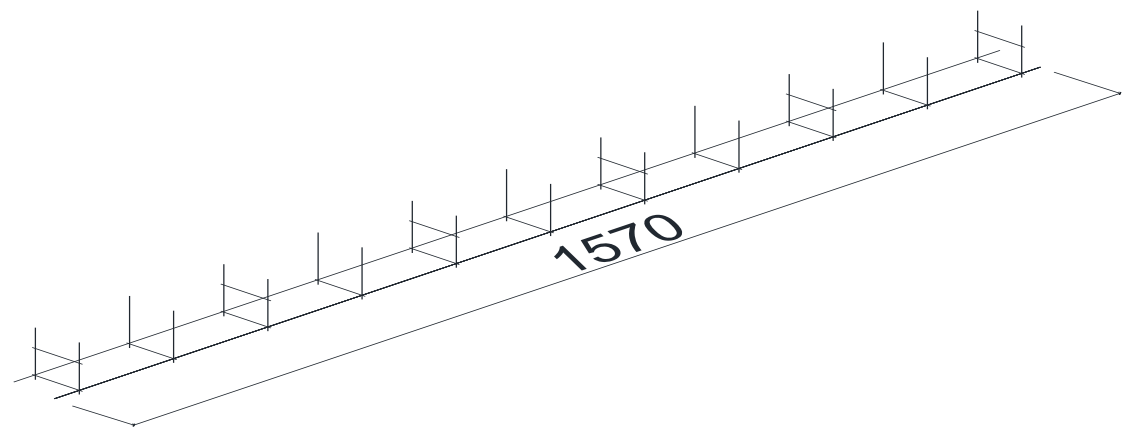

Fig. 3. Isometry of a steel cage frame (SNKR-1). 


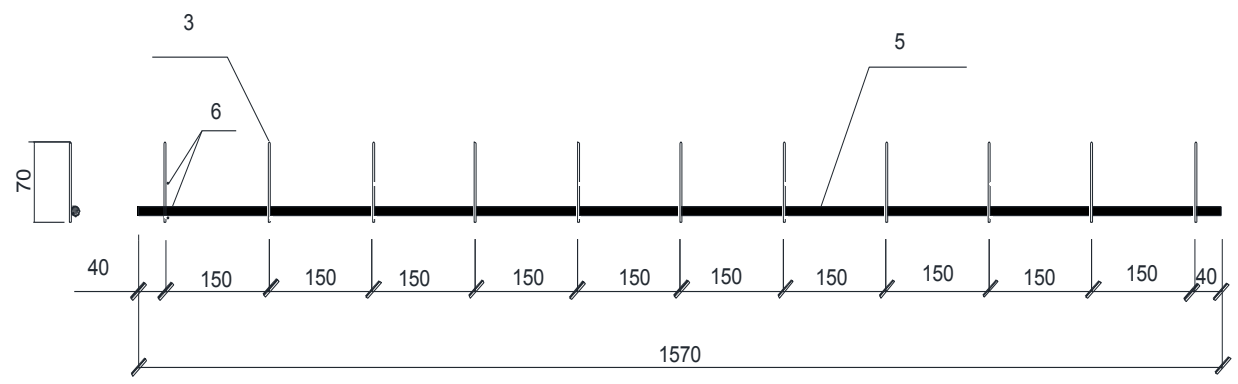

Fig. 4. Steel cage frame. Where: 4- steel pins, 5- longitudinal working reinforcing bar, 6- tenon.

In order to reduce the loads on wooden composite bridge beams during testing, the width and height of the cross section and the length of the experimental samples were halved, which did not lead to a change in the operation of composite bridge beams, since all natural defects are manifested at a width of $100 \mathrm{~mm}$ [13].

Samples for testing wood-rubcon reinforced composite bridge beams (fig. 5). Samples for obtaining the calculated characteristics of rubcon (Figure 6) [14-17].

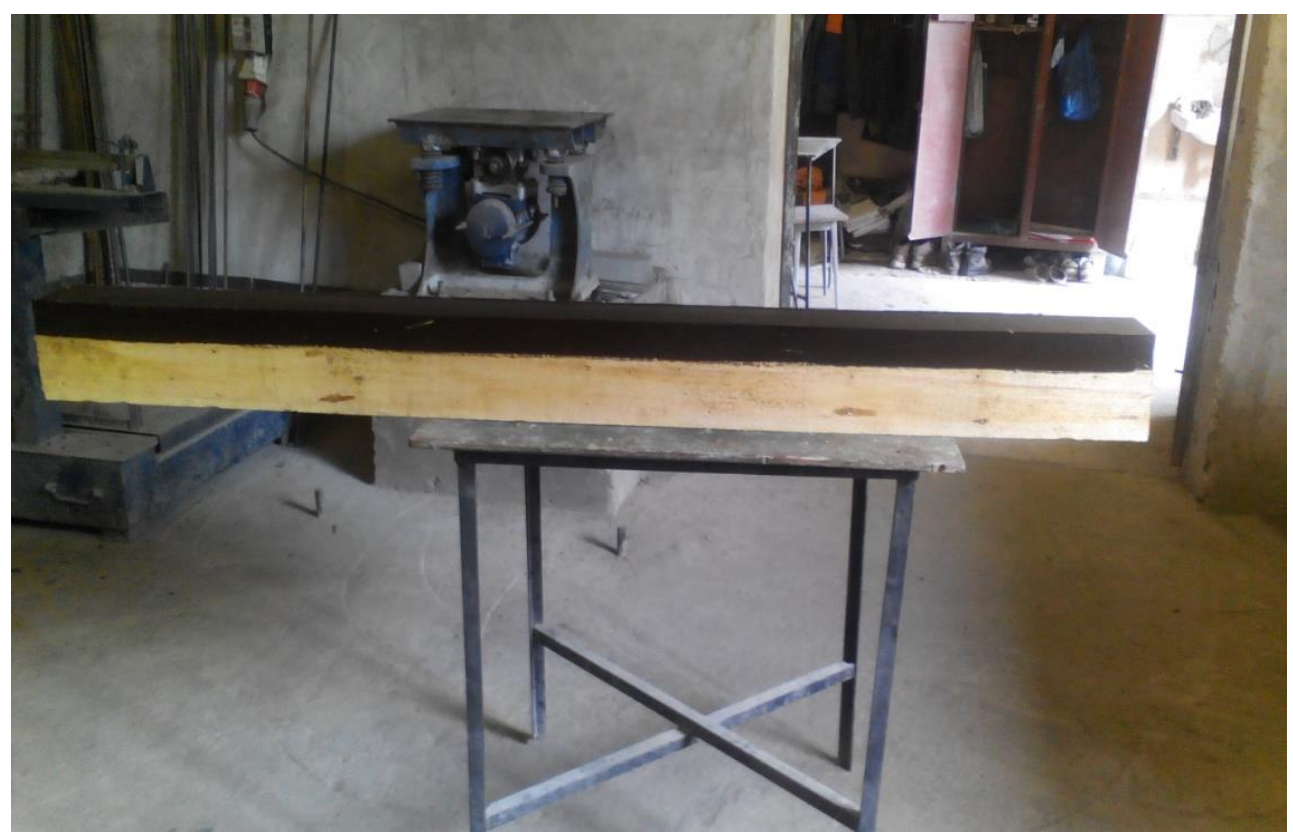

Fig. 5. General view of a wood-rubcon reinforced composite bridge beam. 


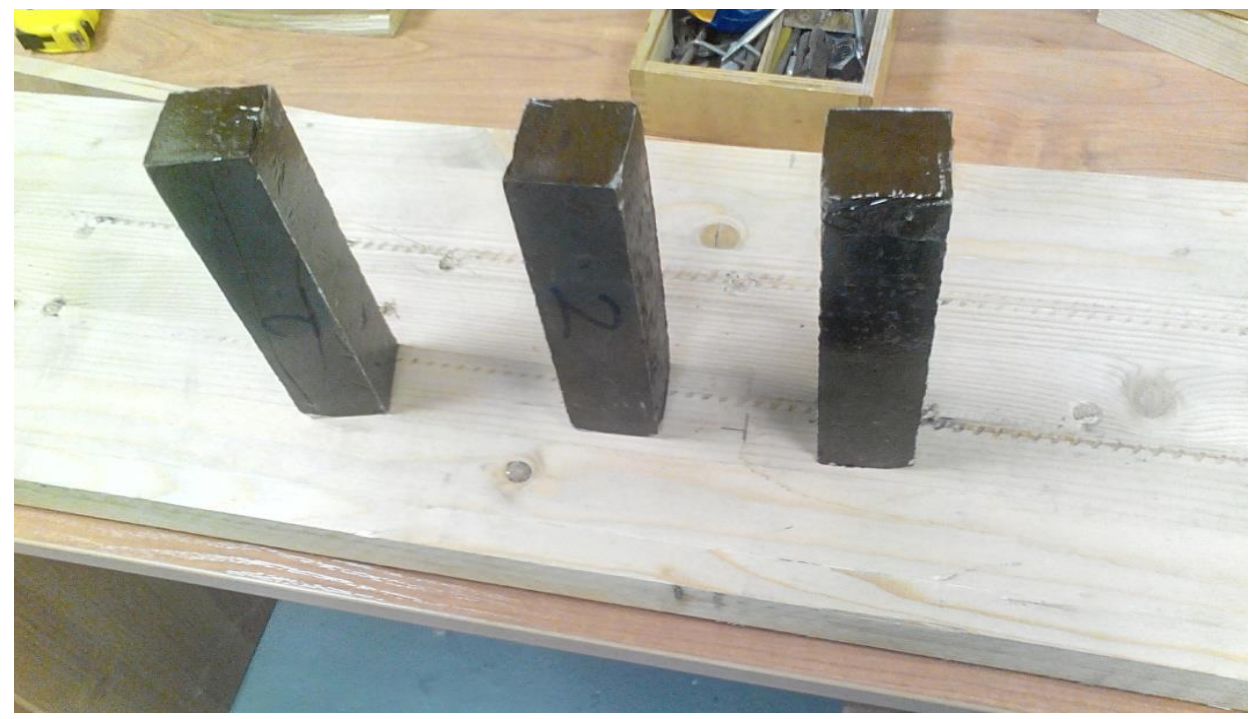

Fig. 6. Samples for obtaining the calculated characteristics of rubcon.

\section{Experimental and theoretical studies of the operation of wood- rubcon reinforced composite bridge beams under static loads}

The purpose of the work was to check the resistance of joints of wood-rubcon reinforced composite bridge beams under static loads. To achieve this goal in the laboratory for testing building constructions of Center for Collective Use (CCU) named after. prof. Yu.M. Borisov, of the Voronezh State Technical University, samples of wood-rubcon reinforced composite bridge beams were tested under static loads (fig. 7, 8).

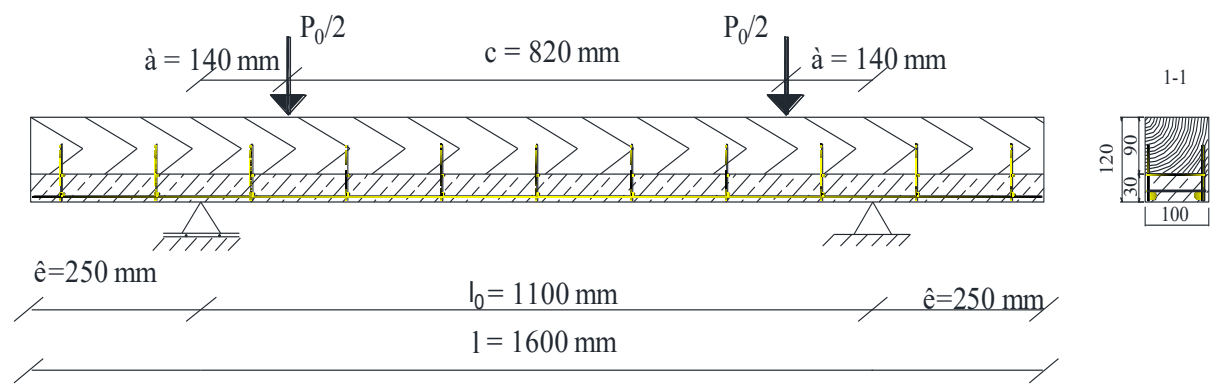

Fig. 7. Design scheme of wood-rubcon reinforced composite bridge beams. 


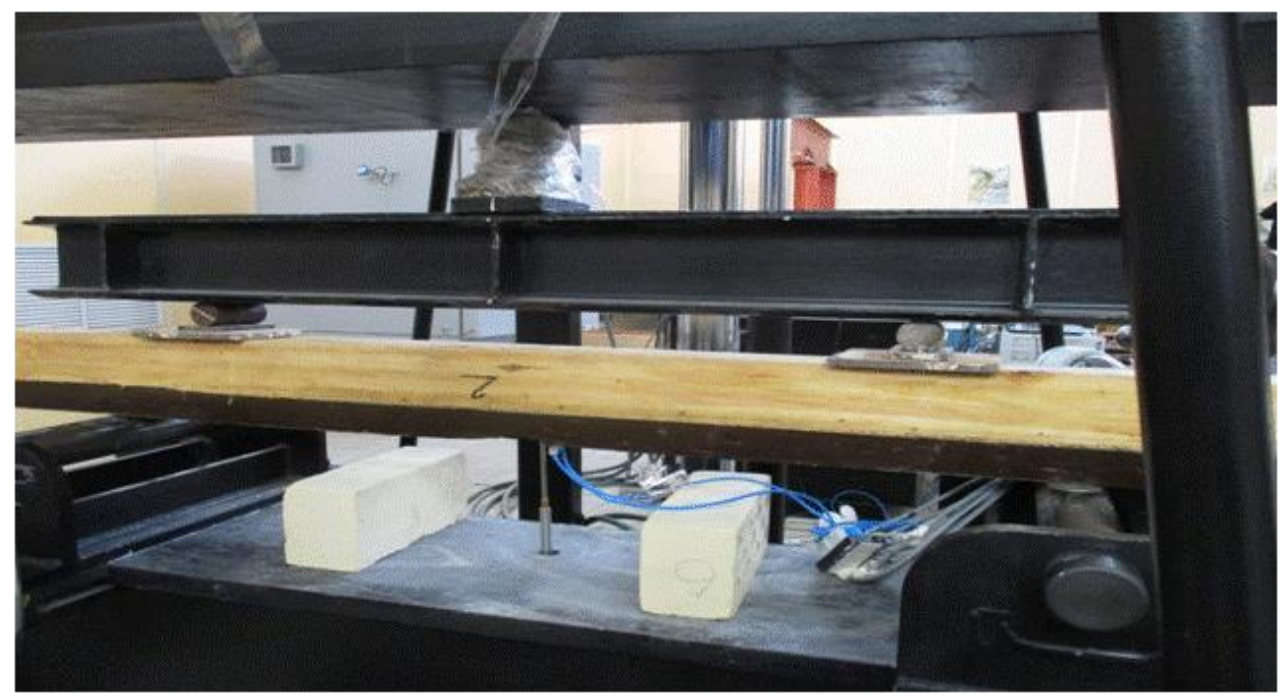

Fig. 8. Loading scheme of wood-rubcon reinforced composite bridge beams.

\subsection{Determination of actual dimensions of wood-rubcon reinforced composite bridge beams}

The following materials were used for the manufacture of wood-rubcon reinforced composite bridge beams:

- wood - pine grade I;

- rubcon;

- reinforcing bar of class A-300.

Initial data:

- wood moisture - $20 \%$;

- cross-sectional height of a wood-rubcon reinforced composite bridge beam, $\mathrm{h}=120 \mathrm{~mm}$;

- width of the cross-section of a wood-rubcon reinforced composite bridge beam, $b=100$ $\mathrm{mm}$;

- height of the cross section of the 1st layer of wood, $h_{d}=90 \mathrm{~mm}$;

- cross-sectional height of the 2 nd layer of rubcon, $h_{k}=30 \mathrm{~mm}$;

- beam length, $1=1600 \mathrm{~mm}$;

- design beam span, $\mathrm{l}_{\mathrm{p}}=1100 \mathrm{~mm}$.

\subsection{Determination of the design characteristics of the material of a wood- rubcon reinforced composite bridge beam}

Design bending resistance of wood $\left(R^{\mathrm{p}}\right)$ equals:

$$
R^{\mathrm{p}}=R^{A} \cdot m_{l t} \cdot \Pi m_{i}
$$

where $R^{A}$ - the design resistance of wood, MPa, shown in table 3 [18], with a humidity of $12 \%$ for loading mode A, according to table 4 [18] in constructions of the 2 nd class of functional purpose, according to Appendix B [18], with a service life of not more than 50 years;

$m_{l t}$ - coefficient of long-term strength corresponding to the mode of loading duration (table 4) $[2]$; 
$\Pi m_{i}$ - the product of the coefficients of the working conditions [18].

$$
\begin{gathered}
R^{A}=24 M P a ; m_{l t}=0,66 ; \Pi m_{i}=1,0 . \\
R^{\mathrm{p}}=24 \cdot 0,66 \cdot 1,0=15,84 \mathrm{MPa}
\end{gathered}
$$

$E_{\mathrm{w}}$ - wood elastic modulus, $E_{\mathrm{w}}=10000 \mathrm{MPa}[18]$;

$G_{\mathrm{w}}$ wood shear design modulus, $G_{\mathrm{w}}=500 \mathrm{MPa}[18]$;

$E_{\mathrm{r}}$ - calculated elastic modulus of rubcon, $E_{\mathrm{r}}=19500 \mathrm{MPa}$ [19];

$E_{\mathrm{s}}$ - design modulus of elasticity of reinforcing bar, $E_{\mathrm{s}}=240000 \mathrm{MPa}$.

\subsection{Determination of the geometric characteristics of the cross section of a wood-rubcon reinforced composite bridge beam}

1) $F_{w r}$ - reduced cross-sectional area of a wood-rubcon reinforced composite bridge beam is determined by the formula

$$
F_{w r}=F_{w}+F_{r} \cdot n_{r}+n_{s} \cdot A_{s}=\underset{\mathrm{m}^{2},}{0,009}+1,95+24 \cdot 0,000308=0,0151
$$

where $F_{w}$ - cross-sectional area of the 1st layer of a wood-rubcon reinforced composite bridge beam $F_{w}=b \cdot h_{w}=0,1 \cdot 0,090=0,009 \mathrm{~m}^{2}$;

$F_{r}$ - Cross-sectional area of the 2 nd layer of a wood-rubcon reinforced composite bridge beam from rubcon

$$
F_{r}=b \cdot h_{r}=0,1 \cdot 0,030=0,003 \mathrm{~m}^{2} ;
$$

$n_{r}$ - coefficient taking into account the ratio of the elastic modulus of the rubcon with the wood

$$
n_{r}=E_{\mathrm{r}} / E_{\mathrm{w}}=19500 / 10000=1,95 ;
$$

$n_{s}$ - coefficient taking into account the ratio of the elastic modulus of reinforcing rod with a wood

$$
n_{s}=E_{\mathrm{s}} / E_{\mathrm{w}}=240000 / 10000=24 ;
$$

$A_{s}$ - cross-sectional area of reinforcing $\operatorname{rod} A_{s}=0,000308 \mathrm{~m}^{2}$

2) $S_{w r}$ - reduced static moment of a wood-rubcon reinforced composite bridge beam is determined by the formula:

$$
\begin{gathered}
S_{w r}=S_{w}+F_{r} \cdot z_{c 2} \cdot n_{r}+n_{s} \cdot A_{s} \cdot z_{c 3}=0,000101+0,000351+0,000406=0,000858 \\
\mathrm{~m}^{3},
\end{gathered}
$$

where $S_{w}$ - static moment of the 1st layer. $S_{w}=b \cdot \frac{h_{w}^{2}}{8}=0,1 \cdot \frac{0,09^{2}}{8}=0,00010 \mathrm{~m}^{3}$;

$z_{c 2}$ - distance from the center of gravity of 1 layer of wood to the center of gravity of the rubcon layer.

$$
z_{c 2}=\frac{h_{w}}{2}+\frac{h_{r}}{2}=\frac{90}{2}+\frac{30}{2}=60 \mathrm{~mm}=0,06 \mathrm{~m} ;
$$

$z_{c 3}$ - distance from the center of gravity of 1 layer of wood to the center of gravity of the reinforcing bar. 


$$
Z_{c 3}=\frac{h_{w}}{2}+h_{r}-\mathrm{a}=\frac{90}{2}+30-20=55 \mathrm{~mm}=0,055 \mathrm{~m} .
$$

3) $I_{w r}$ - the reduced moment of inertia of the wood-rubcon reinforced composite bridge beam is determined by the formula

$$
\begin{gathered}
I_{w r}=I_{w}+I_{r}+A_{r} \cdot z_{c 2}^{2} \cdot n_{r}+n_{s} \cdot A_{s} \cdot z_{c 3}{ }^{2}= \\
=0,00000607+0,000000225+0,0000052+0,0000055=0,000017 \mathrm{~m}^{4},
\end{gathered}
$$

where $I_{w}$-moment of inertia of the 1 st layer of the beam,

$$
I_{w}=b \cdot \frac{h_{w}^{3}}{12}=0,1 \cdot \frac{0,090^{3}}{12}=0,0000607 \mathrm{~m}^{4} .
$$

4) $W_{w r}$ - the reduced moment of resistance of a wood-rubcon reinforced composite bridge beam is determined by the formula

$$
W_{w r}=\frac{2 \cdot I_{w r}}{h}=\frac{2 \cdot 0,000017}{0,12}=0,00028 \mathrm{~m}^{3}
$$

\subsection{Determination of the bearing capacity of a wood-rubcon reinforced composite bridge beam}

3.4.1 Determination of the bearing capacity of a wood-rubcon reinforced composite bridge beam from the calculated normal bending stresses

$$
\sigma=\frac{\mathrm{M}}{W_{\mathrm{wr}}}=\frac{P \cdot 0,140}{2 \cdot W_{w r}} \leq R^{\mathrm{p}}
$$

where $M=\frac{P}{2} \cdot 0,140 ; P$ - design load.

From formula (7), we assume that the voltage is equal to the rated resistance and we determine the rated load

$$
P=\frac{R^{\mathrm{p}} \cdot 2 \cdot W_{\mathrm{wr}}}{0,140}=\frac{15,84 \cdot 1000 \cdot 2 \cdot 0,00028}{0,140}=63,36 \mathrm{kN}
$$

3.4.2 Determination of the bearing capacity of a wood-rubcon reinforced composite bridge beam from the estimated tangential stresses in bending

$$
\tau=\frac{Q \cdot S}{I \cdot b}=\frac{3 Q}{2 F} \leq R_{\mathrm{c}}
$$

where $\mathrm{Q}=\frac{P}{2}$, then $\tau=\frac{3 P}{4 F} \leq R_{\mathrm{c}}$

From formula (9), we assume that the shear stress is equal to the design resistance when shearing and determine the design load

$$
P=\frac{4 F \cdot R_{\mathrm{c}}}{3}=\frac{4 \cdot 0,151 \cdot 1,78 \cdot 1000}{3}=35,83 \mathrm{kN}
$$

3.4.3 Determination of the bearing capacity of a wood-rubcon reinforced composite bridge beam from the stiffness condition

The standard deflection of the beam is $1 / 170$ span, hence 


$$
\frac{f}{l}=\frac{P \cdot \mathrm{a}^{3} \cdot l_{\mathrm{p}}}{24 \cdot \mathrm{E}_{w} \cdot I_{w r} \cdot \gamma_{f}} \cdot\left(3 \cdot \frac{l_{\mathrm{p}}^{2}}{\mathrm{a}^{2}}-4\right)
$$

where $\gamma_{f}=1,1$ - reliability factor

$$
P=\frac{48 \cdot \mathrm{E}_{w} \cdot I_{w r} \cdot \gamma_{f} \cdot l_{\mathrm{p}}}{\left(3 \cdot \frac{l_{\mathrm{p}}^{2}}{\mathrm{a}^{2}}-4\right) \cdot \mathrm{a}^{3}}=\frac{48 \cdot 10^{7} \cdot 0,000017 \cdot 1,1 \cdot 1 \cdot 1,1}{\left(\frac{3 \cdot 1,1^{2}}{0,140^{2}}-4\right) \cdot 170 \cdot(0,140)^{3}}=32,50 \mathrm{kN}
$$

The calculated load is equal to the minimum calculated by the formulae (8), (10), (12).

Destructive load is determined by multiplying the design load value by the material safety factor $\gamma_{\mathrm{M}}=1,15$, then

$$
P_{\text {destr.d }}=P \cdot \gamma_{\mathrm{M}}=32,50 \cdot 1,15=37,38 \mathrm{kN}
$$

\subsection{Drawing up a design diagram of a wood-rubcon reinforced composite bridge beam and determining the forces}

Design scheme. The design scheme (Figure 9) of a wood-rubcon reinforced composite bridge beam is taken in the form of a single-span beam on two supports.

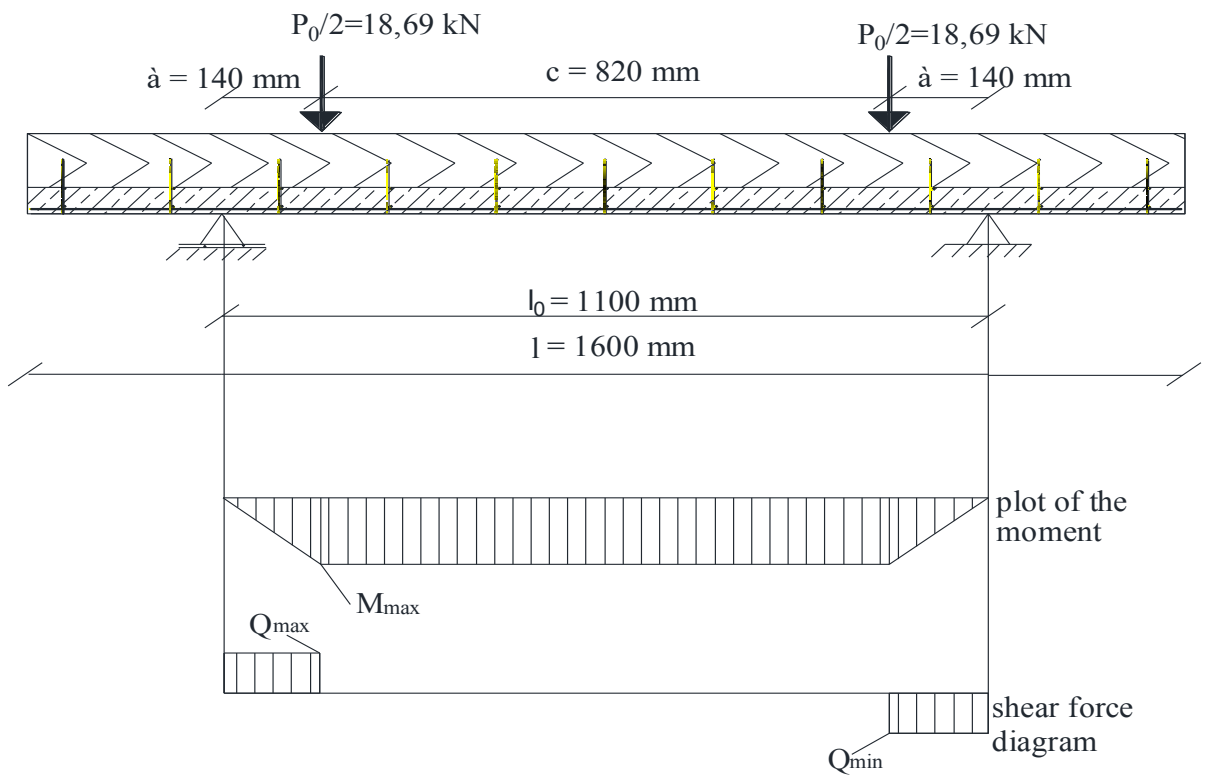

Fig. 9. Design scheme of a wood-rubcon reinforced composite bridge beam.

The maximum bending moment is determined by the formula:

$$
M=\frac{P_{\text {destr.d. }}}{2} \cdot a=\frac{37,38}{2} \cdot 0,140=2,61 \mathrm{kN} \cdot \mathrm{m},
$$

where $a$ - the distance from the axes of support of the beam to the place of application of the load, equal to $140 \mathrm{~mm}$

$$
Q=\frac{P_{\text {destr.d }}}{2}=\frac{37,38}{2}=18,69 \mathrm{kN}
$$




\subsection{Verification of a wood-rubcon reinforced composite bridge beam according to groups I and II of the limiting state}

a) Checking beam according to the I ultimate state of strength:

$$
\sigma=\frac{\mathrm{M}}{W \mathrm{wr}} \leq \mathrm{R}^{\mathrm{p}},
$$

where $\mathrm{R}^{\mathrm{p}}$ - design bending resistance, $\mathrm{MPa}[2]$; $\mathrm{M}$ - maximum bending moment.

$$
\sigma=\frac{M}{W w r}=\frac{2,61}{0,00028}=9,32 \mathrm{MPa} \leq \mathrm{R}^{\mathrm{p}}=15,84 \mathrm{MPa}
$$

b) Checking the beam according to the II limit state for deflection:

$$
f=\frac{f_{0}}{k}\left[1+C\left(\frac{h}{l}\right)^{2}\right] \leq\left[f_{u}\right]
$$

where $h$ - maximum section height; $l$ - span of beam; $k$ - a coefficient taking into account the influence of variability of the height of the section, taken equal to 1 for a beam of constant cross section; $C$ - coefficient taking into account the influence of shear deformation from shear force, determined by the formula $C=15,4+3,8 \cdot \beta=19$, 2, where $\beta=1 ; f_{u}=\frac{1}{170} l$ - ultimate deflection $/ 10 / ; f_{0}$ - beam deflection, determined by the formula

$$
\begin{gathered}
f_{0}=\frac{P_{0} \cdot \mathrm{a}^{3} \cdot \mathrm{l}_{\mathrm{p}}^{2}}{48 \mathrm{E}_{w} \cdot I_{w r} \cdot \gamma_{f}} \cdot\left(3 \cdot \frac{l_{\mathrm{p}}^{2}}{\mathrm{a}^{2}}-4\right)=\frac{37,38 \cdot 0,14^{3} \cdot 1,12}{48 \cdot 10000 \cdot 1000 \cdot 0,000017 \cdot 1,1} \cdot\left(3 \cdot \frac{1,1^{2}}{0,14^{2}}-4\right)=0,0022 \\
f=\frac{0,0022}{1}\left[1+19,2\left(\frac{0,12}{1,1}\right)^{2}\right]=0,0027 \mathrm{~m} \leq\left[f_{u}=\frac{1}{170} 1,1=0,0064 \mathrm{~m}\right]
\end{gathered}
$$

\section{Test procedure for a wood-rubcon reinforced composite bridge beam under short-term loads}

\subsection{Test results of a wood-rubcon reinforced composite bridge beam}

The loading scheme and arrangement of devices (fig. 10,11) corresponded to the test conditions. The load on each of the two simultaneously loaded beams was $37.38 \mathrm{kN}$ and was determined when calibrating the lever plants of the second order using the model dynamometer DOSM-3-5. The loading of the sample is carried out in steps. The magnitude of the step is $0,25 \cdot P_{\text {test }}$.

Tests of wooden reinforced composite bridge bars were carried out at the Voronezh State Technical University in the laboratory for testing building constructions of the CCU named after prof. Yu.M. Borisov. 


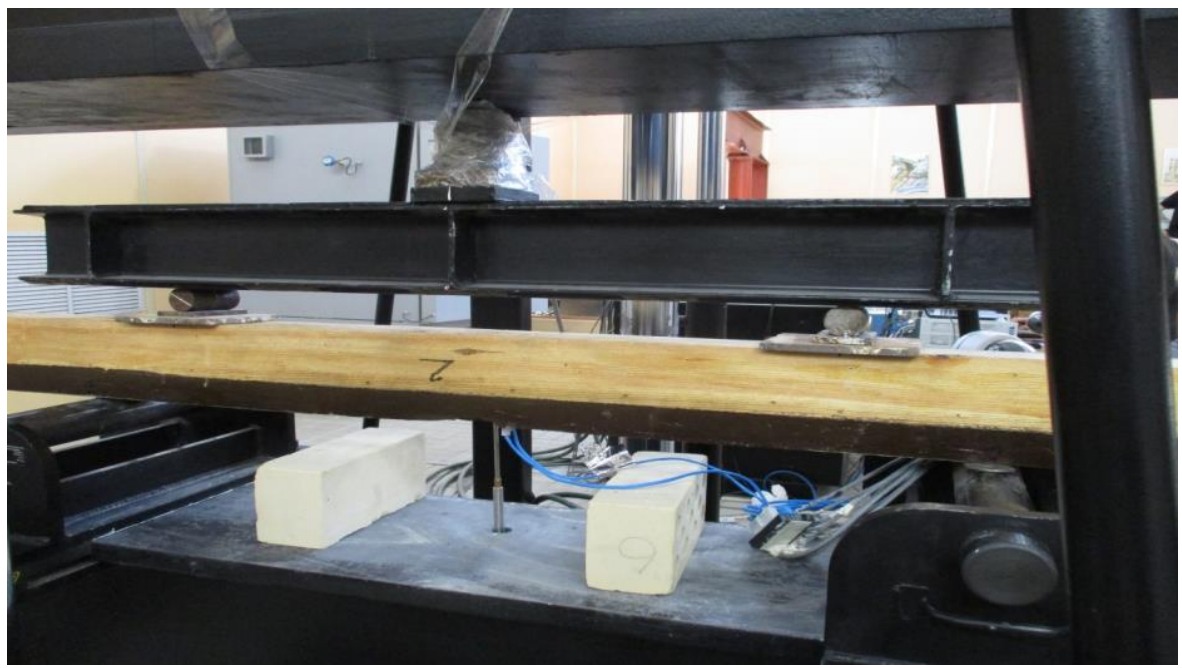

Fig. 10. Loading scheme of a wood-rubcon reinforced composite bridge beam.

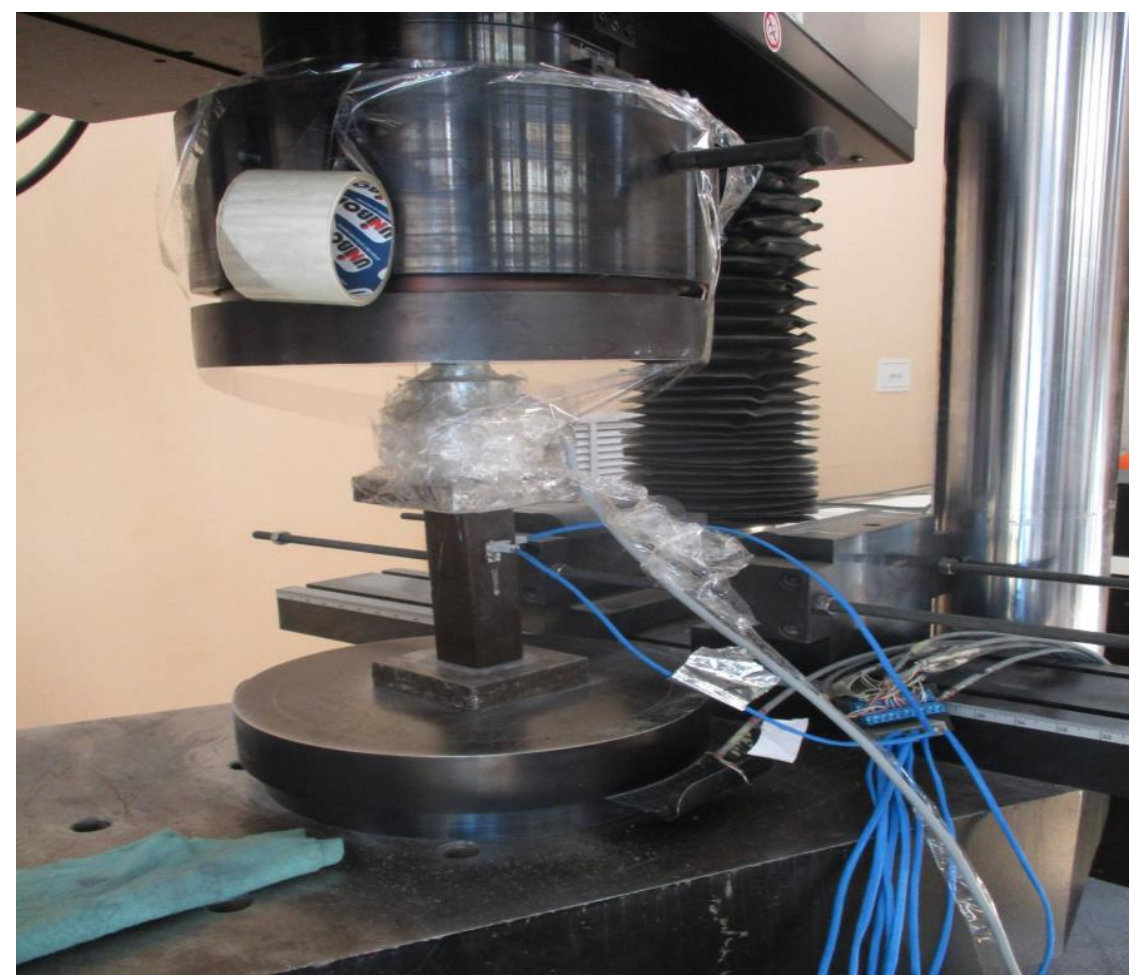

Fig. 11. Test pattern of rubcon concrete sample for deformation.

Deformation graphs are shown in the Figure 12. The maximum deflections were 6.201 $\mathrm{mm}$ at load $37,68 \mathrm{kN}$. 


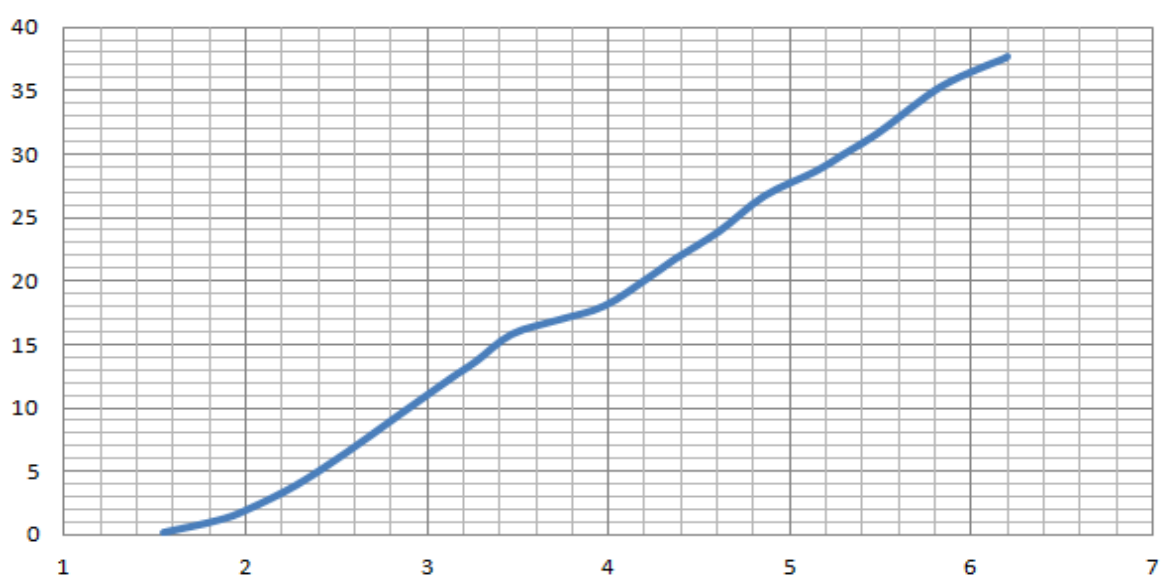

Fig. 12. Deformation of a wood-rubcon reinforced composite bridge beam.

To obtain the calculated characteristics of the rubcon, prism samples were made with a dimension size of $40 \mathrm{~mm} \times 40 \mathrm{~mm} \times 160 \mathrm{~mm}$ [19] (Figure 6). We tested them for compressive strength. We plotted the graph of the relationship between stress and strain (Figure 13).

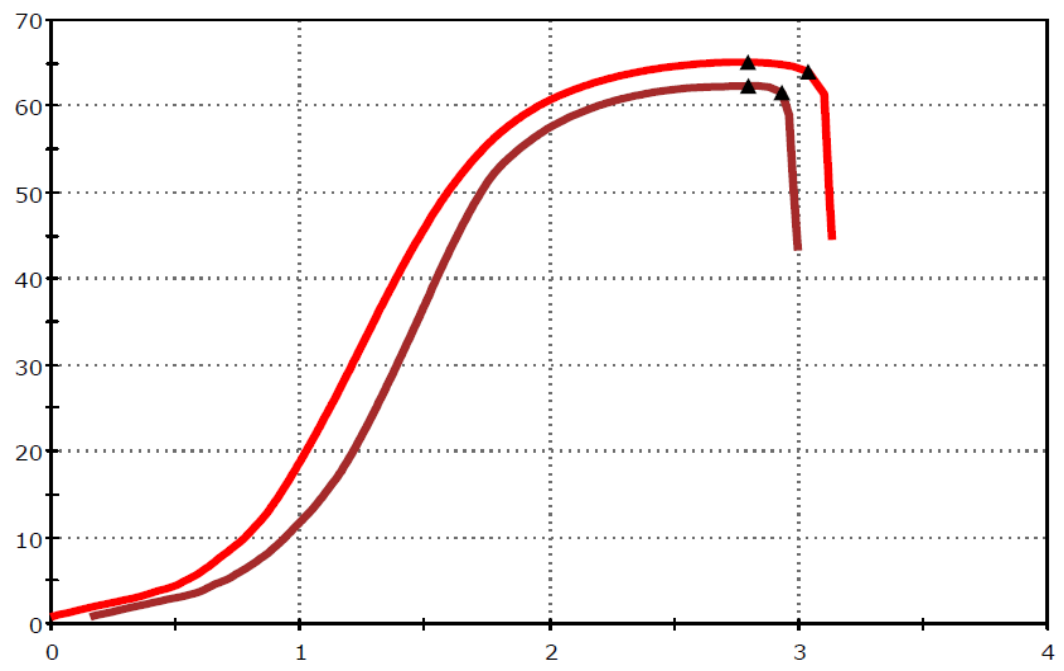

Fig. 13. Graph of the relationship between load and deformation.

\section{Conclusions}

1. For the first time, experimental data have been obtained on the performance of woodrubcon reinforced composite bridge beams.

2. An optimal methodology has been developed for experimental studies of wood-rubcon reinforced composite bridge beams.

3. An experimental deflection of wood-rubcon reinforced composite bridge beams was obtained.

4. A method for calculating wood-rubcon reinforced composite bridge beams has been developed. 


\section{References}

1. P. Larrinaga, C. Chastre, J.T. San-José, L. Garmendi, Composites Part B: Engineering 55, 528-536 (2013)

1. J. Brozzetti, Journal of Constructional Steel Research 55(1-3), 229-243 (2000)

2. N.F. Pan, Automation in Construction 17(8), 958-965 (2008)

2. S. Franke, B. Franke, A.M. Harte, Construction and Building Materials 9730, 2-13 (2015)

3. I. Giongo, G. Schiro, D. Riccadonna, Composite Structures 226, 111195 (2019)

4. D.W. Radford, D. Van Goethem, R.M. Gutkowski, M.L. Peterson, Construction and Building Materials 16(7), 417-425 (2002)

5. M. Brunetti, I.P. Christovasilis, M. Micheloni, M. Nocetti, B. Pizzo, Composites Part B: Engineering 156, 212-219 (2019)

6. J.L. Miotto, A. Alves Dias, Composite Structures 128, 145-154 (2015)

7. A.S. Mosallam, Composites Part B: Engineering 87, 196-213 (2016)

8. O. Benjeddou, O. Limam, M.B. Ouezdou, Engineering Structures 44, 312-321 (2012)

9. R. Beleznai G.L. Szepesi, Z. Siménfalvi, Procedia Structural Integrity 16, 59-66 (2019)

3. J.R. Demitz, D.R. Mertz, J.W. Gillespie, Journal of Bridge Engineering 8(2), 73-83 (2003)

10. L. Dahoua, F. Boymatov, Studia Geotechnica et Mechanica 40(3), 202-207 (2018)

11. A.E. Polikutin, Yu.B. Potapov, A. Levchenko, O. Perekal'skiy, Advances in Intelligent Systems and Computing 983, 586-599 (2019)

12. S. Pinaev, V.Gavshin, N. Chernikov, International Multi-Conference on Industrial Engineering and Modern technologies electronic edition. IOP Conference Series: Materials Science and Engineering, 032012 (2018)

13. A.E. Polikutin, A.V. Levchenko, D.N. Korotkih, International Multi-Conference on Industrial Engineering and Modern technologies electronic edition. IOP Conference Series: Materials Science and Engineering, 022040 (2018)

14. Yu.B. Potapov, Yu.M. Borisov, Bulletin of the Department of Construction Sciences of the RAASN 2, 190-196 (1999)

15. Code of practice SP 64.13330.2011. Wooden structures. Updated version of BRaR II25-80 (Ministry of Regional Development of Russia, Moscow, 2011)

16. Yu. B. Potapov, V.P. Selyaev, B.M. Lupaev, Composite building constructions (Stroyizdat, Moscow, 1984) 